\title{
Long-term outcome after laparoscopic creation of a neovagina in patients with Mayer-Rokitansky-Küster- Hauser syndrome by a modified Vecchietti procedure
}

\author{
J. Keckstein • O. Kandolf • G. Rauter • G. Hudelist
}

Received: 3 May 2007 / Accepted: 4 July 2007 / Published online: 6 September 2007

(C) Springer-Verlag 2007

\begin{abstract}
Several conservative and surgical methods have been proposed for patients with Mayer-Rokitansky-KüsterHauser (MRKH) syndrome. The technique described by Vecchietti is a combination of both dilatation and surgery. We describe a minimally invasive modification of this approach including dissection of the vesico-rectal septum and present long-term patient outcome. Eight patients who underwent surgery at our department between 1996 and 2005 for MRKH syndrome were included in the present analysis. Post-operative follow-up and a semi-structured telephone interview were performed to obtain information on neovaginal functionality, immediate and long-term postoperative outcome, sexual function and physiological and psychological well-being evaluated on a 10-point scale and by the Sintonen $15 \mathrm{D}$ questionnaire. After a median postoperative (median operation time: $88 \mathrm{~min}$, range: 63-116 min) follow-up period of 40.3 months (range: 1884 months) without major complications and a median post-operative stay of 13.8 days (range: 6-15 days), a functional neovagina was created in seven of eight patients. Median vaginal length at the time of discharge from the hospital ranged between 7 and $10 \mathrm{~cm}$ (median: $9.6 \mathrm{~cm}$ ) and reached $11.5 \mathrm{~cm}$ (range: $5-15 \mathrm{~cm}$ ) at the time of evaluation. Except for one patient who neither had regular sexual intercourse nor used the vaginal dilator, sexual intercourse was quoted as satisfactory in six cases (one patient still used the dilator only). Patients reported an improvement of quality of life (mean: 8.1, range: 5-10) and self-confidence (8.1, range: $5-10)$ and general well-being evaluated by the
\end{abstract}

\footnotetext{
J. Keckstein $(\bowtie) \cdot$ O. Kandolf $\cdot$ G. Rauter $\cdot$ G. Hudelist $(\bowtie)$ Department of Obstetrics and Gynaecology, Villach Medical Center, Nikolaigasse 43, 9500 Villach, Austria e-mail: joerg.keckstein@lkh-vil.or.at e-mail: gernot_hudelist@yahoo.de
}

Sintonen 15D questionnaire (average score of $1.8, \mathrm{SD}=$ 0.06). The laparoscopic-assisted Vecchietti procedure with dissection of the vesico-rectal septum is a safe and effective method for creation of a neovagina in MRKH patients.

Keywords Mayer-Rokitansky-Küster-Hauser syndrome . Vecchietti procedure $\cdot$ Laparoscopy

\section{Introduction}

Mayer-Rokitansky-Küster-Hauser syndrome (MRKH) is a rare congenital abnormality of the female genital tract (incidence 1:5000) based on agenesis of the paramesonephric duct (Müllerian duct) which is associated with a short or aplastic vagina, a rudimentary or absent uterus in the presence of a functioning ovary, normogonadotrophic sex steroid levels, normal secondary sexual characteristics and a normal female karyotype [15]. As a consequence, patients experience primary amenorrhoea and are unable to practice normal sexual intercourse, which often leads to psychological problems based on a decreased self-esteem. In order to create a functioning neovagina in patients with MRKH, several methods have been described to date. Non-surgical approaches include dilatation of the vaginal groove with a hand-held dilator in a squatting position first described by Frank $[13,20]$ or by passive dilatation using the patient's own weight according to the method of Ingram [8]. In addition, various surgical methods have been described such as the creation of a split-thickness skin graft which covers a stent inserted into the space between bladder and rectum (McIndoe and Bannister) [11], the use of the patient's own peritoneum for vaginal reconstruction (Davydov technique) [5] or creation of a neovagina with a sigmoid graft [4]. Although there is no standardized 
method, the majority of surgically treated cases (up to 300) have been described by Vecchietti [18, 19] who proposed a combination of the surgical and conservative approaches by performing a laparotomy, dissection of the vesico-rectal septum followed by fixation of a vaginal "dilatation olive" with two sutures passing from the abdominal wall through the pseudohymenal septum. To date, several authors have described laparoscopic modifications of the Vecchietti method in which the vesico-rectal septum is protruded with a thread-bearing cutting needle laparoscopically down to the vaginal groove, followed by placement of a vaginal dilatation instrument which is attached to the abdominal wall with preperitoneal traction sutures. Although both laparotomic and laparoscopic procedures yield similar outcomes [1], intra-operative complications such as perforation of the bladder or the rectum with the thread-bearing needle have been described [6]. We report the long-term outcome of a minimally invasive approach based on the original laparotomic variant described by Vecchietti which includes laparoscopic dissection of the vesico-rectal septum.

\section{Materials and methods}

\section{Patient data}

Eight patients with MRKH syndrome defined by normal external genitalia, vaginal agenesis combined with uterine aplasia or existence of a rudimentary uterus in the presence of ovaries and normal secondary sexual characteristics who underwent surgery at our department from 1996 to 2005 were included in the present analysis following detailed consent. All patients presented with primary amenorrhoea and the desire to start sexual activity. Mean age at the time of presentation was 21.9 years (range: 18-24 years). Before surgery, all patients were informed about other available surgical and non-surgical procedures such as laparotomic sigmoid vaginoplasty, lining of the neovaginal space with a split-thickness skin graft according to McIndoe [11], creation of a neovagina using the patient's peritoneum as a lining (Davydov procedure) or conservative creation of a neovagina according to the method described by Frank [13]. In addition, all women underwent sonographic examination of the pelvis and the urinary system, and no further anomalies of the urinary tract or skeletal system were observed. One of eight patients performed dilatation of the hymenal septum for 6 months before surgery. Patient characteristics are depicted in Table 1. Data on the operative procedure and the post-operative period such as operating time, intra-operative complications, post-operative need for analgetics and duration of the hospital stay were obtained from patient records. In order to evaluate the functional
Table 1 Description of patients $(n=8)$ included in the study

Characteristics

Age (mean)

Urinary tract anomalies

Skeletal anomalies

Localization of the ovaries

Orthotopic

Heterotopic

21.9 years (range: $18-24)$
None
None
8
None

results of the procedure (length of the neovagina, vaginal epithelialization) all patients were requested to visit their gynaecologists on a 6- to 12-month basis. A semi-structured telephone interview was undertaken to examine complications in the post-operative period, sexual function (postoperative vaginal dilator use, frequency and possibility of intercourse, vaginal lubrication) and changes in psychological well-being based on a self-constructed questionnaire (quantification on a 10-point scale; $0=$ not satisfactory to $10=$ entirely satisfactory) and on the Sintonen $15 \mathrm{D}$ healthrelated quality of life questionnaire [16].

\section{Surgical procedure}

All subjects were operated by the same surgeon (J.K.) under general anaesthesia. After laparoscopic access (subumbilical insertion of a 10-mm trocar and laparoscope, insertion of three additional ports, suprapubically and lateral to the inferior epigastric arteries), the vesico-rectal space was dissected with monopolar scissors down to the pseudohymenal septum after instillation of a vasoconstrictive agent (Fig. 1). In order to avoid perforation of the bladder or the rectum, the vaginoscope was positioned at the pseudohymenal septum to facilitate the dissection procedure and to properly visualize the pseudohymenal membrane (Fig. 2a). A Deschamps needle carrying traction sutures connected to a vaginal dilator according to Pelzer [14] or Vecchietti [19] was then used to perforate the pseudohymenal membrane from the outer vaginal side (Fig. 2b). The thread was then retrieved and withdrawn by a laparoscopic grasper after creation of a extra-peritoneal tunnel beginning from the port at either side via the anterior abdominal wall and ending at the perforated pseudohymenal membrane between the rectum and bladder. Following this, the dissected vesico-rectal space was closed with laparoscopic polydioxanone (PDS) sutures and cystoscopy was performed to rule out vesical injury. Tension was increased day by day by pulling each suture equally on either side and fixing the thread to the abdominal wall by a tensioning device according to Vecchietti [19] or Pelzer [14] (Fig. 3). After formation of the neovagina (6-10 days), the tensioning thread was removed and patients were informed to use vaginal dilators with increasing size after 


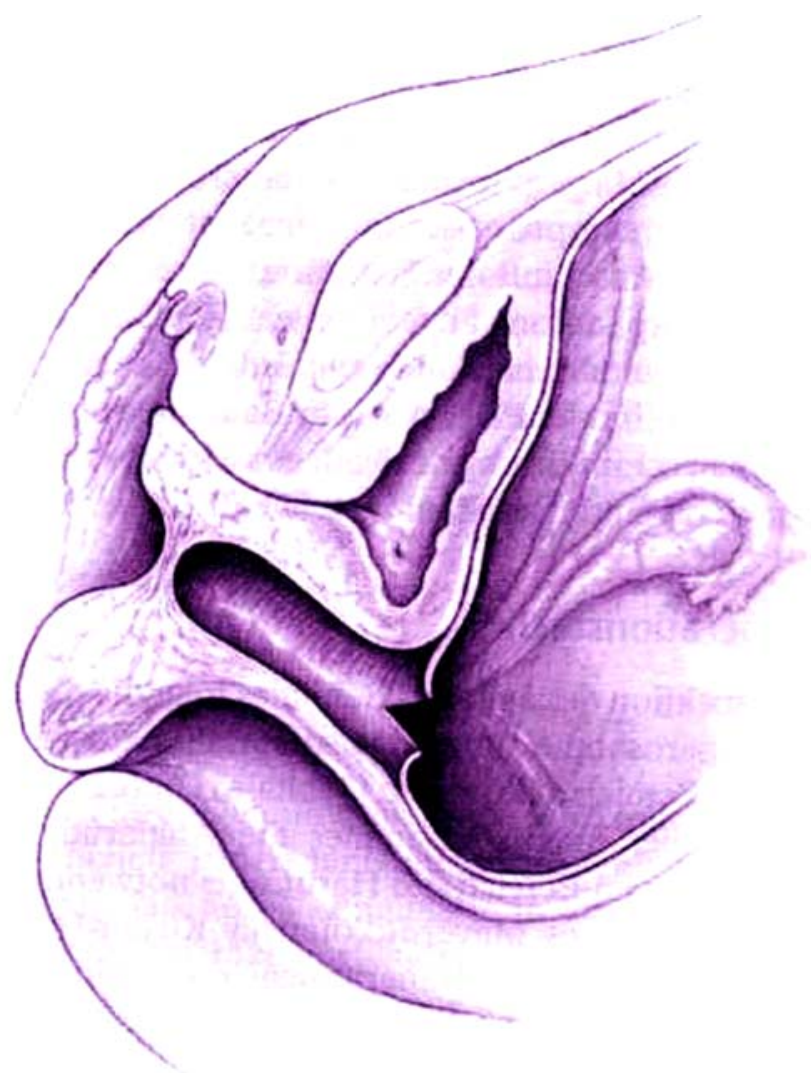

Fig. 1 After instillation of a vasoconstrictive agent, the vesico-rectal septum is dissected with monopolar scissors down to a pseudohymenal membrane under constant visualization of the bladder and the rectum

topical instillation of oestrogenic cream for at least 3 months until onset of regular sexual intercourse.

\section{Results}

Complications and post-operative period

No intra- or post-operative complications were observed in any of the eight patients undergoing the surgical procedure. Post-operative recovery was rapid although post-operative

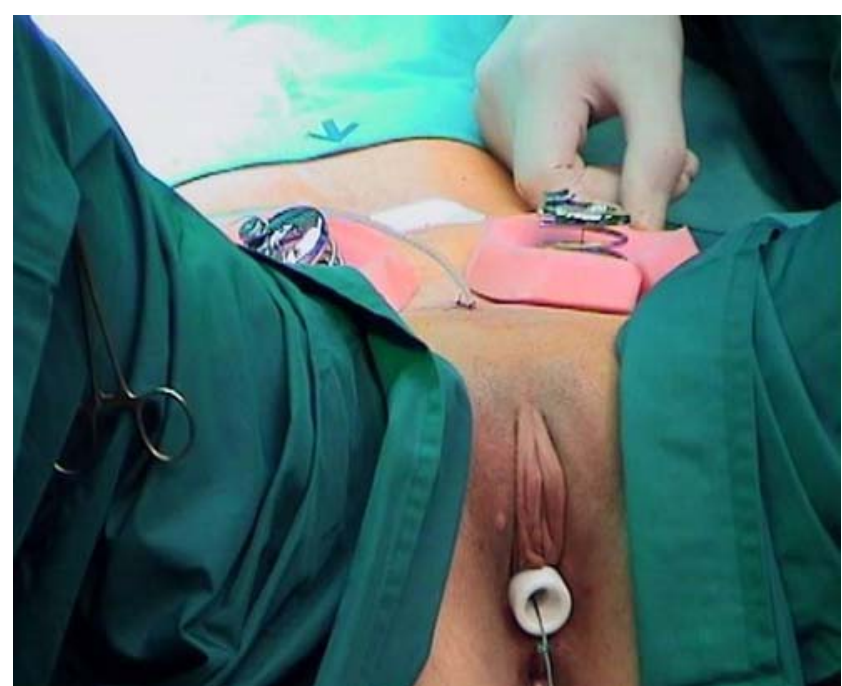

Fig. 3 Final post-operative situs with vaginal dilatation olive and abdominal tension device. Tension is increased day by day by pulling each suture equally on either side

need for analgetics was present in six of eight patients and ranged from 5 days to intermittent use of oral pain-relieving medication for up to 24 weeks (two of eight patients) with a median time of 11 weeks. Patients were discharged home between days 6 and 15 with a median post-operative stay of 13.8 days.

\section{Anatomical and functional outcome}

The average operation time was $88 \mathrm{~min}$ and ranged between 63 and $116 \mathrm{~min}$. Median time of post-operative follow-up was 40.3 months (range: 18-84 months). An adequate vaginal length, defined as $\geq 7 \mathrm{~cm}$ could be achieved in all except one patient who neither started regular sexual activity nor regularly used vaginal dilators and ranged between 7 and $10 \mathrm{~cm}$ at the time of discharge from the hospital (median: $9.6 \mathrm{~cm}$ ) and reached $11.5 \mathrm{~cm}$ (range: $5-15 \mathrm{~cm}$ ) at the time of evaluation. Except for two patients, six of eight patients started sexual intercourse 224 months after surgery (median: 6.8 months). In a case of irregular sexual contact, dilator use was performed without
Fig. 2 After dissection of the vesico-rectal septum, the pseudohymenal membrane is visualized (a). Following this, a traction suture-bearing Deschamps needle is used to perforate the pseudohymenal membrane from the outer vaginal side (b)
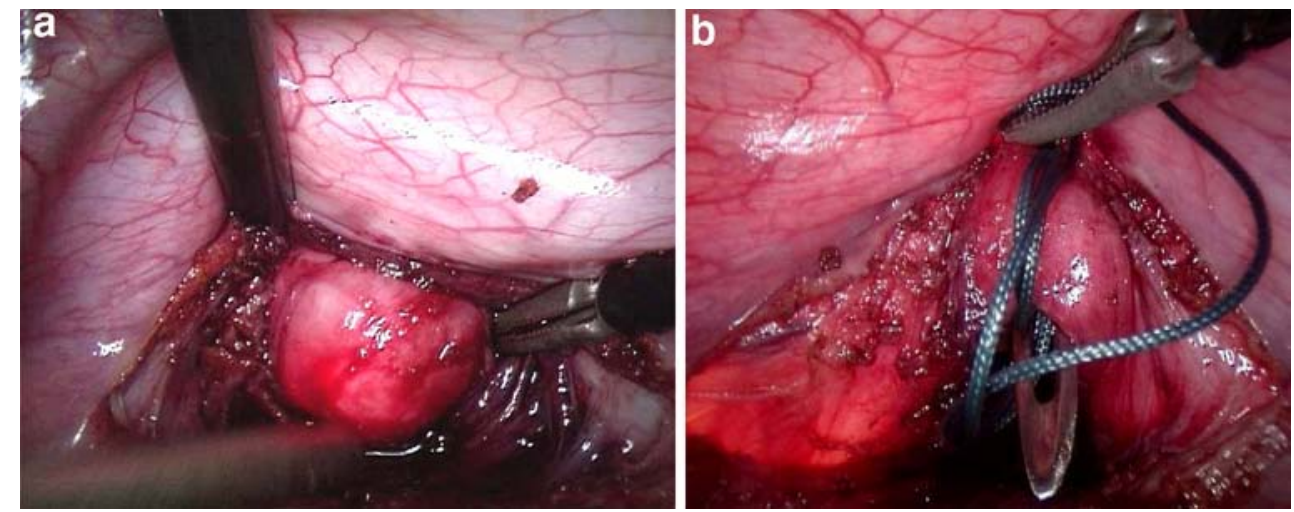
complications by one patient. Persistent use of vaginal lubricants before sexual intercourse or dilator use was noted in four cases. Although sexual intercourse was quoted as satisfactory in six of six cases, four of six patients sometimes experienced minor pain during sexual activity. Quantification of satisfactory sexual activity on a 10-point scale revealed a mean value of 7.8 (range: 2-10). Patients reported an improvement of quality of life (mean: 8.1, range: 5-10) and self-confidence (8.1, range: 5-10) after completion of the surgical procedure. In addition, general well-being and sexual health were quantified by the Sintonen 15D questionnaire and revealed an average score of $1.8(\mathrm{SD}=0.06)$ compared to the corresponding average value of the normal female population reported by Sintonen et al. [16] of $0.96(\mathrm{SD}=0.05)$. When patients were asked if they would undergo the operation again knowing all advantages and possible disadvantages, all except one patient agreed they would have the procedure performed again. The one patient who would refuse to undergo the operation a second time reported neither sexual intercourse nor the regular use of vaginal dilators as advised, which might have contributed to the unsatisfactory post-operative result.

\section{Discussion}

Based on the variety and modifications of surgical techniques for vaginal reconstruction, there is a constant debate on the efficacy of either technique proposed by certain authors. In general, several lines of evidence indicate that the procedure described by Davydov is suitable for creation of a neovagina in patients with previous unsuccessful vaginal surgery $[9,12]$. On the other hand, conservative approaches according to Frank $[13,20]$ or Ingram [8] have been shown to be successful in patients with a pre-existent vaginal groove who do not wish to undergo surgery [15]. The use of an isolated segment of the sigmoid colon for vaginal construction has also been reported to yield satisfying post-operative outcomes [3, 4]. However, some reports point at major intra- and postoperative complications such as necrosis of the sigmoid graft, intestinal anastomosis dehiscence, prolapse of the neovagina or persistent vaginal outflow [2, 7, 17]. The present technique based on the method by Vecchietti [18] in its laparoscopic modification has been shown to be a safe and quick procedure with minor intra- and post-operative complications $[6,10]$. In contrast to other authors, we perform dissection of the vesico-rectal space instead of protruding a thread-bearing needle through the septum. The advantage of this technique is preparation and visualization of the anatomical structures, i.e. bladder and rectum, which can be injured during protrusion of the needle. In addition, creation of a preformed space between bladder and rectum might facilitate the post-operative dilatation process. In our series of eight patients, no intra- or post-operative complications occurred. Although four of six patients with regular sexual intercourse sometimes experienced minor pain during sexual activity, the procedure was clearly beneficial in improving quality of life and self-esteem, even in patients who still used vaginal dilators and did not take up sexual activity yet. Only one patient did not appear to profit from the procedure with a post-operative reduction of vaginal length and unsatisfying intercourse. However, the patient neither took up regular sexual activity nor intermittent use of the dilator, which is a precondition for preservation of neovaginal functionality.

\section{Conclusions}

Taken together, the laparoscopic variant of the Vecchietti operation is a safe and effective method for creation of a neovagina in patients with MRKH. However, regular postoperative dilation of the reconstructed organ either by sexual intercourse or by use of dilators is necessary for satisfying long-term results of the procedure.

\section{References}

1. Borruto F, Chasen ST, Chervenak FA, Fedele L (1999) The Vecchietti procedure for surgical treatment of vaginal agenesis: comparison of laparoscopy and laparotomy. Int J Gynaecol Obstet 64:153-158

2. Christensen B (2002) Minimally invasive methods to create a neovagina (in German). Zentralbl Gynakol 124:313-316

3. Communal PH, Chevret-Measson M, Golfier F, Raudrant D (2003) Sexuality after sigmoid colpopoiesis in patients with Mayer-Rokitansky-Kuster-Hauser Syndrome. Fertil Steril 80:600-606

4. Darai E, Toullalan O, Besse O, Potiron L, Delga P (2003) Anatomic and functional results of laparoscopic-perineal neovagina construction by sigmoid colpoplasty in women with Rokitansky's syndrome. Hum Reprod 18:2454-2459

5. Davydov SN (1969) Colpopoeisis from the peritoneum of the uterorectal space (in Russian). Akush Ginekol (Mosk) 45:55-57

6. Fedele L, Bianchi S, Zanconato G, Raffaelli R (2000) Laparoscopic creation of a neovagina in patients with Rokitansky syndrome: analysis of 52 cases. Fertil Steril 74:384-389

7. Freundt I, Toolenaar TA, Jeekel H, Drogendijk AC, Huikeshoven FJ (1994) Prolapse of the sigmoid neovagina: report of three cases. Obstet Gynecol 83:876-879

8. Ingram JM (1981) The bicycle seat stool in the treatment of vaginal agenesis and stenosis: a preliminary report. Am J Obstet Gynecol 140:867-873

9. Ismail IS, Cutner AS, Creighton SM (2006) Laparoscopic vaginoplasty: alternative techniques in vaginal reconstruction. BJOG 113:340-343

10. Keckstein J, Buck G, Sasse V, Tuttlies F, Ulrich U (1995) Laparoscopic creation of a neovagina: modified Vecchietti method. Endosc Surg Allied Technol 3:93-95 
11. Klingele CJ, Gebhart JB, Croak AJ, DiMarco CS, Lesnick TG, Lee RA (2003) McIndoe procedure for vaginal agenesis: longterm outcome and effect on quality of life. Am J Obstet Gynecol 189:1569-1572, discussion 1572-1573

12. Langebrekke A, Istre $\mathrm{O}$, Busund $\mathrm{B}$, Sponland $\mathrm{G}$, Gjonnaess $\mathrm{H}$ (1998) Laparoscopic assisted colpoiesis according to Davydov. Acta Obstet Gynecol Scand 77:1027-1028

13. Murray JM, Gambrell RD Jr (1979) Complete and partial vaginal agenesis. J Reprod Med 22:101-105

14. Pelzer V, Graf M (1989) The segmented phantom insert for the formation of a neovagina according to Vecchietti (in German). Geburtshilfe Frauenheilkd 49:977-980

15. Roberts CP, Haber MJ, Rock JA (2001) Vaginal creation for müllerian agenesis. Am J Obstet Gynecol 185:1349-1352, discussion 1352-1353
16. Sintonen $H$ (2001) The 15D instrument of health-related quality of life: properties and applications. Ann Med 33:328-336

17. Toolenaar TA, Freundt I, Huikeshoven FJ, Drogendijk AC, Jeekel $\mathrm{H}$, Chadha-Ajwani S (1993) The occurrence of diversion colitis in patients with a sigmoid neovagina. Hum Pathol 24:846-849

18. Vecchietti $G$ (1965) Creation of an artificial vagina in Rokitansky-Kuster-Hauser syndrome (in Italian). Attual Ostet Ginecol 11:131-147

19. Vecchietti G (1979) The neovagina in the Robitansky-KusterHauser syndrome (in French). Rev Med Suisse Romande 99: 593-601

20. Wabrek AJ, Millard PR, Wilson WB Jr, Pion RJ (1971) Creation of a neovagina by the Frank nonoperative method. Obstet Gynecol $37: 408-413$ 